\title{
Immune Thrombocytopenia in Adults: Modern Approaches to Diagnosis and Treatment
}

\author{
Hanny Al-Samkari, MD ${ }^{1}$ David J. Kuter, MD, DPhil ${ }^{1}$ \\ 1 Division of Hematology, Massachusetts General Hospital, Harvard \\ Medical School, Boston, Massachusetts \\ Address for correspondence Hanny Al-Samkari, MD, Division of \\ Hematology, Massachusetts General Hospital, Suite 118, Room 112, \\ Zero Emerson Place, Boston, MA 02114 \\ Semin Thromb Hemost 2020;46:275-288. \\ (e-mail: hal-samkari@mgh.harvard.edu).
}

\begin{abstract}
Immune thrombocytopenia (ITP) is an autoimmune bleeding disorder affecting approximately 1 in 20,000 people. Patients typically present with clinically benign mucocutaneous bleeding, but morbid internal bleeding can occur. Diagnosis remains clinical, possible only after ruling out other causes of thrombocytopenia through history and laboratory testing. Many adult patients do not require treatment. For those requiring intervention, initial treatment of adult ITP is with corticosteroids, intravenous immunoglobulin, or intravenous anti-RhD immune globulin. These agents are rapidacting but do not result in durable remissions in most patients. No corticosteroid has

Keywords

- platelets

- immune thrombocytopenia

- diagnosis

- treatment

- corticosteroids

- intravenous immunoglobulin

- splenectomy

- thrombopoietin receptor agonist

- rituximab

- fostamatinib demonstrated superiority to others for ITP treatment. Subsequent treatment of adult ITP is typically with thrombopoietin receptor agonists (TPO-RAs; romiplostim or eltrombopag), rituximab, or splenectomy. TPO-RAs are newer agents that offer an excellent response rate but may require prolonged treatment. The choice between subsequent treatments involves consideration of operative risk, risk of asplenia, drug side-effects, quality-of-life issues, and financial costs. Given the efficacy of medical therapies and the rate of spontaneous remission in the first year after diagnosis, splenectomy is frequently deferred in modern ITP treatment algorithms. Fostamatinib (a tyrosine kinase inhibitor recently approved by the U.S. Food and Drug Administration) and several older immunosuppressive agents (azathioprine, cyclophosphamide, cyclosporine, danazol, dapsone, mycophenolate mofetil, and the Vinca alkaloids) may be useful in patients with disease unresponsive to standard therapies or in specific clinical circumstances. This comprehensive review explores diagnostic considerations and surveys new and old treatment options for adults with ITP.
\end{abstract}

Immune thrombocytopenia (ITP) is an autoimmune bleeding disorder of excessive reticuloendothelial platelet destruction with inadequate compensatory platelet production. ITP results from the dual action of platelet autoantibodies that opsonize platelets and induce megakaryocyte apoptosis as well as direct $\mathrm{T}$ cell-mediated megakaryocyte and platelet destruction. ${ }^{1-3}$ Modern definitions of ITP require a platelet count $<100$ $\times 10^{9} / \mathrm{L}$ for diagnosis in a patient with no other underlying causes for thrombocytopenia., 4 Primary ITP occurs in the absence of a clinically identifiable source of immune dysregu- lation, while secondary ITP occurs in the setting of such a source (e.g., systemic lupus erythematosus or chronic lymphocytic leukemia). Diagnosis of ITP remains clinical, as there is no "gold standard" diagnostic test. Initial ITP treatment has remained largely unchanged for several decades, with corticosteroids and intravenous immunoglobulin (IVIG) typically used to manage newly diagnosed patients and chronic patients requiring urgent rescue therapy. ${ }^{4,5}$ However, subsequent treatment options have evolved considerably over the past decade. While most of the older treatments worked to reduce platelet published online December 12, 2019
Issue Theme Acquired Platelet Dysfunction-Laboratory and Clinical Implications; Guest Editors: Anne-Mette Hvas, MD, PhD, Julie Brogaard Larsen, MD, $\mathrm{PhD}$, and Leonardo Pasalic, MBBS, PhD.
Copyright $\odot 2020$ by Thieme Medical Publishers, Inc., 333 Seventh Avenue, New York, NY 10001, USA. Tel: +1(212) 760-0888.
DOI https://doi.org/ 10.1055/s-0039-1700512. ISSN 0094-6176. 
destruction via nonspecific action on the immune system, newer agents target more specifically the pathophysiology of ITP by improving platelet production or decreasing platelet destruction. In this review, we will assess modern practices in ITP diagnosis and treatment synthesizing the best available evidence and expert opinion.

\section{Diagnosis of Immune Thrombocytopenia}

\section{Clinical Presentation}

The incidence of ITP is approximately 1 in 20,000 people and increases with age. ${ }^{6,7}$ It is slightly more common in females. ${ }^{7}$ The initial presentation of ITP is highly variable, from incidentally discovered asymptomatic mild thrombocytopenia to severe, life-threatening bleeding. Patients who present with profound thrombocytopenia (platelet count $<20 \times 10^{9} / \mathrm{L}$ and usually $<10 \times 10^{9} / \mathrm{L}$ ) often have evidence of benign mucocutaneous hemorrhage, such as petechiae, ecchymoses, and oral mucosal blood blisters. Though clinically benign, this frequently brings the patient to clinical attention. Significant musculoskeletal bleeding, as occurs in severe coagulation factor deficiencies, generally does not occur, but there is a low, albeit important, risk of gastrointestinal bleeding and intracranial bleeding in profoundly thrombocytopenic ITP patients. Bleeds may occur secondary to trauma, other pathology (such as a tumor), or spontaneously. Intracranial bleeding typically presents as intracerebral hemorrhage and is the most common cause of ITP-related death, with a 50 to $80 \%$ mortality in patients $>60$ years of age and up to $20 \%$ mortality in patients $<40$ years of age. ${ }^{8,9}$ In a meta-analysis of 17 studies, the rate of fatal bleeding in ITP was estimated at 0.0162 to 0.0389 cases per patient-year. ${ }^{9}$ Rapid-acting treatment modalities such as corticosteroids and IVIG are administered to treat and prevent such serious bleeding complications in the acute setting.

While numerous factors impact the degree of thrombocytopenia that is likely to cause bleeding, most ITP patients do not present with mucocutaneous bleeding or clinically significant hemorrhage until the platelet count is $<30 \times 10^{9} / \mathrm{L}$ and many patients remain asymptomatic in the 20 to $29 \times 10^{9} / \mathrm{L}$ or even the 10 to $19 \times 10^{9} /$ L range. $^{7}$ The most common symptom in ITP aside from bleeding is fatigue, which occurs in 20 to $40 \%$ of patients. ${ }^{10}$ Although the etiology is not entirely clear, fatigue can markedly affect quality of life in ITP patients and may even be an indication for treatment, which may be very effective at alleviating fatigue. ${ }^{11}$

\section{Diagnostic Testing}

Although there is no test capable of reliably diagnosing ITP, a laboratory evaluation is recommended at diagnosis to screen for potential causes of secondary ITP, uncover infections resulting in thrombocytopenia that may resolve with proper treatment, and rule out other causes of thrombocytopenia. ${ }^{4,5}$ Alternative causes of thrombocytopenia, and the recommended assessments to rule out these disorders, are listed in - Table 1.

All adults presenting with new suspected ITP should undergo a comprehensive history and physical examination with the following laboratory studies: complete blood count, peripheral blood film, human immunodeficiency virus serology, hepatitis C serology, and comprehensive metabolic panel (including transaminases, bilirubin, and alkaline phosphatase). ${ }^{5}$ The peripheral blood film should be examined to rule out evidence of other causes of thrombocytopenia as can be seen such as fragmented erythrocytes (suggesting thrombotic microangiopathy or disseminated intravascular coagulation [DIC]) or atypical leukocytes (suggestive of myeloid or lymphoid malignancy). Giant platelets are frequently seen on peripheral blood film in ITP. Quantitative immunoglobulin levels can be obtained in patients for whom a primary immunodeficiency (e.g., common variable immunodeficiency) is suspected or prior to IVIG infusion but are not required in all patients. ${ }^{5}$ Bone marrow evaluation is not indicated unless patients have additional unexplained cytopenia, a significant family history of thrombocytopenia or myeloid malignancies, or poor response to typical initial treatment options (corticosteroids, IVIG, anti-D immune globulin). ${ }^{4,5}$ While ELISA-based glycoprotein-specific direct platelet autoantibody testing has been repeatedly demonstrated to have a high specificity in the $>80$ to $90 \%$ range, $^{12}$ it is not recommended for routine diagnosis owing to its poor sensitivity. ${ }^{4,5}$ The sensitivity of platelet autoantibody testing for ITP diagnosis may be improved with adherence to recent laboratory platelet autoantibody testing guidelines, ${ }^{13}$ but this remains under investigation. Other methods of platelet autoantibody testing, such as flow cytometric detection of platelet-associated immunoglobulin $\mathrm{G}$, are additionally not recommended. ${ }^{4,5}$

Routine direct antiglobulin testing or testing for antinuclear antibodies, antiphospholipid antibodies, antithyroid antibodies, or thyroid function is not recommended, ${ }^{4,5}$ although targeted testing may have utility in certain patients given other medical history and findings on history and physical examination. For example, direct antiglobulin testing is appropriate in patients with a concomitant anemia with an elevated reticulocyte count or in those for whom intravenous anti-RhD immune globulin is being considered for treatment. Routine testing for thrombopoietin (TPO) levels, reticulated platelets, bleeding time, serum complement, or platelet survival is similarly not recommended for diagnostic purposes. ${ }^{4,5}$ There may be a role of serum TPO in predicting response to thrombopoietin receptor agonist (TPO-RA) therapy, ${ }^{14}$ which is discussed in more detail later.

\section{Classification of Immune Thrombocytopenia}

The chronicity of ITP has been defined according to the report of the international ITP working group (IWG). ${ }^{15}$ Patients with ITP for less than 3 months are considered to have newly diagnosed ITP; an alternative explanation for their isolated thrombocytopenia ( - Table 1) supplanting the ITP diagnosis will eventually be found in approximately $50 \%$ of these patients. Persistent ITP is defined as disease duration $>3$ months but $\leq 12$ months, and chronic ITP is defined as disease duration $>12$ months. These classifications are relevant as chronicity impacts disease manifestations (e.g., intracranial hemorrhage is much less common in patients with chronic ITP). ${ }^{8,9}$ 
Table 1 Alternative etiologies of isolated thrombocytopenia to consider in the diagnosis of immune thrombocytopenia

\begin{tabular}{|c|c|c|}
\hline Alternative diagnosis & Recommended evaluation & Additional testing to consider \\
\hline $\begin{array}{l}\text { Chronic infections } \\
\text { - HIV } \\
\text { - HCV } \\
\text { - Helicobacter pylori }\end{array}$ & $\begin{array}{l}\text { Serologic evaluation for HIV, HCV, and } \\
\text { H. pylori }\end{array}$ & $\begin{array}{l}\text { More sensitive } H \text {. pylori testing (e.g., } \\
\text { urea breath test, stool antigen) may } \\
\text { be considered in patients from } \\
\text { high-prevalence locations }\end{array}$ \\
\hline $\begin{array}{l}\text { Systemic autoimmunity (especially } \\
\text { systemic lupus erythematosus and } \\
\text { antiphospholipid antibody syndrome) }\end{array}$ & History and physical examination & $\begin{array}{l}\text { Targeted serologic testing (e.g., } \\
\text { antinuclear antibody, anti-double- } \\
\text { strand DNA antibody, antiphospholi- } \\
\text { pid antibodies) in patients with } \\
\text { concerning findings on history and } \\
\text { physical }\end{array}$ \\
\hline Chronic liver disease & $\begin{array}{l}\text { History and physical examination } \\
\text { Liver panel (transaminases, bilirubin, } \\
\text { alkaline phosphatase) }\end{array}$ & $\begin{array}{l}\text { Liver imaging (e.g., ultrasound) in } \\
\text { cases suspicious for occult liver } \\
\text { disease }\end{array}$ \\
\hline Splenomegaly & History and physical examination & $\begin{array}{l}\text { Abdominal ultrasound to assess } \\
\text { spleen size }\end{array}$ \\
\hline Malignancy & $\begin{array}{l}\text { History and physical examination } \\
\text { Age-appropriate cancer screening }\end{array}$ & $\begin{array}{l}\text { Targeted evaluation as indicated } \\
\text { based on history and physical } \\
\text { examination }\end{array}$ \\
\hline $\begin{array}{l}\text { Primary bone marrow disorders } \\
\text { (e.g., myelodysplastic syndrome, aplastic } \\
\text { anemia, leukemia, Gaucher's disease) }\end{array}$ & $\begin{array}{l}\text { Complete blood count } \\
\text { Peripheral blood film }\end{array}$ & $\begin{array}{l}\text { Bone marrow evaluation can be con- } \\
\text { sidered in patients with unexplained } \\
\text { concomitant anemia, leukopenia, or } \\
\text { leukocytosis or steroid- and IVIG- } \\
\text { nonresponsive patients }\end{array}$ \\
\hline $\begin{array}{l}\text { Substances and drugs } \\
\text { - Prescription medications } \\
\text { (e.g., valproic acid) } \\
\text { - Heparin agents (precipitation of } \\
\text { heparin-induced thrombocytopenia) } \\
\text { - Over-the-counter medications/ } \\
\text { supplements } \\
\text { - Alcohol abuse } \\
\text { - Tonic water (containing quinine) } \\
\text { - Environmental toxin exposure }\end{array}$ & History & $\begin{array}{l}\text { Targeted laboratory evaluation as } \\
\text { indicated based on history }\end{array}$ \\
\hline $\begin{array}{l}\text { Heritable thrombocytopenias, e.g., } \\
\text { Bernard-Soulier syndrome, MYH9-related } \\
\text { disease, type IIB von Willebrand disease, } \\
\text { Upshaw-Shulman syndrome }\end{array}$ & $\begin{array}{l}\text { Family history } \\
\text { Peripheral blood film }\end{array}$ & $\begin{array}{l}\text { Specific coagulation or genetic test- } \\
\text { ing in potentially suspicious cases }\end{array}$ \\
\hline $\begin{array}{l}\text { Acute viral infections (e.g., Epstein-Barr } \\
\text { virus, cytomegalovirus) and immunologic } \\
\text { stimuli (e.g., vaccinations, transfusions) }\end{array}$ & History and physical examination & $\begin{array}{l}\text { Viral serologies/PCR if specific viral } \\
\text { infection(s) suspected }\end{array}$ \\
\hline $\begin{array}{l}\text { Chronic disseminated intravascular } \\
\text { coagulation or low-grade thrombotic } \\
\text { microangiopathy }\end{array}$ & $\begin{array}{l}\text { History and physical examination } \\
\text { Complete blood cell count } \\
\text { Coagulation studies (prothrombin time, } \\
\text { partial thromboplastin time, fibrinogen, } \\
\text { D-dimer) } \\
\text { Peripheral blood film }\end{array}$ & $\begin{array}{l}\text { Targeted imaging or invasive evalua- } \\
\text { tion as indicated based on initial } \\
\text { evaluation }\end{array}$ \\
\hline
\end{tabular}

Abbreviations: HCV, hepatitis C virus; HIV, human immunodeficiency virus; IVIG, intravenous immunoglobulin; PCR, polymerase chain reaction. Note: Recommended evaluation to rule out each of these disorders is described.

The severity of ITP has additionally been defined in American Society of Hematology (ASH) clinical practice guidelines. ${ }^{4}$ Patients requiring any disease-directed treatment for clinical bleeding manifestations are designated severe ITP and those requiring additional medical treatment following splenectomy are designated refractory ITP. Patients with refractory ITP have higher rates of mortality. ${ }^{16}$ While official terminology defines refractory ITP as failure of splenectomy, in modern practice splenectomy is performed only on a small minority of patients. Therefore "refractory" is often used to describe patients who have failed multiple lines of therapy (one of which may be splenectomy), although this is not a definition present in published guidelines.

Response to treatment has also been defined by the IWG. A "response" $(\mathrm{R})$ is defined as a platelet count between 30 and $100 \times 10^{9} / \mathrm{L}$ and at least double the baseline platelet count and a "complete response" (CR) is defined as a platelet count $>100 \times 10^{9} /$ L following treatment. $^{15}$ There is no widely 
accepted definition of "remission" in ITP. Most investigations examining ITP variably define "partial remission" and "complete remission" based on arbitrary platelet count thresholds. ${ }^{17}$

\section{Initial Treatment of Immune Thrombocytopenia}

ITP treatment can be broadly divided into initial/acute treatment and subsequent treatment, which may require long-term administration. Each treatment has one or more distinct effects on the pathophysiology of ITP (-Fig. 1). Initial/acute treatment is administered on initial presentation or acute relapse in a patient with profound thrombocytopenia and/or bleeding manifestations. Agents in this category (corticosteroids, IVIG, IV anti-D immune globulin) necessarily have a relatively rapid onset of action (typically 1-2 days) and are not generally considered appropriate longterm treatments. Most adults with ITP will not maintain a normal platelet count after initial treatments alone, and those that relapse with bleeding or very low platelet counts proceed to subsequent treatments. Subsequent treatments to achieve long-term disease control or remission include TPO-RAs, rituximab, splenectomy, fostamatinib, and others.

\section{Indications for Treatment}

In ITP, as well as other thrombocytopenic conditions, treatment-triggering platelet count thresholds are frequently sought out or formulated by clinicians. Indeed, thresholds for treatment are described in consensus guidelines; for example, the ASH 2011 ITP guidelines suggest treatment should be given to newly diagnosed patients with platelet counts $<30 \times 10^{9} / \mathrm{L}^{4}$ But multiple studies suggest a poor correlation, if any at all, between platelet count and bleeding in ITP in patients with platelet counts $>10 \times 10^{9} / \mathrm{L}^{18-20}$ This is consistent with other studies that have demonstrated normal thrombin generation ${ }^{21}$ and bleeding time ${ }^{22}$ in patients with platelet counts as low as $10 \times 10^{9} /$ L. Additionally, platelets from patients with ITP are often larger and more functional than normal platelets, such that the overall platelet mass is higher than expected for a given platelet count. ${ }^{22}$

Given this data, we will always treat any bleeding ITP patient (regardless of platelet count), patients with a platelet count $<10 \times 10^{9} / \mathrm{L}$, and most patients with a platelet count 10 to $19 \times 10^{9} / \mathrm{L}$. Beyond this, treatment indications are personalized for individual patients. Most patients with chronic ITP tolerate platelet counts in the 20 to $50 \times 10^{9} / \mathrm{L}$ range without spontaneous bleeding events. Consideration of platelet counts during prior bleeding events, activity level, lifestyle/profession (and associated trauma risks), costs and potential side effects of treatment, and patient preferences must be considered in all patients. In those patients with known platelet dysfunction, an additional hemostatic defect, planned surgery, trauma, or need for antiplatelet therapy, anticoagulation, or chemotherapy, higher platelet counts are

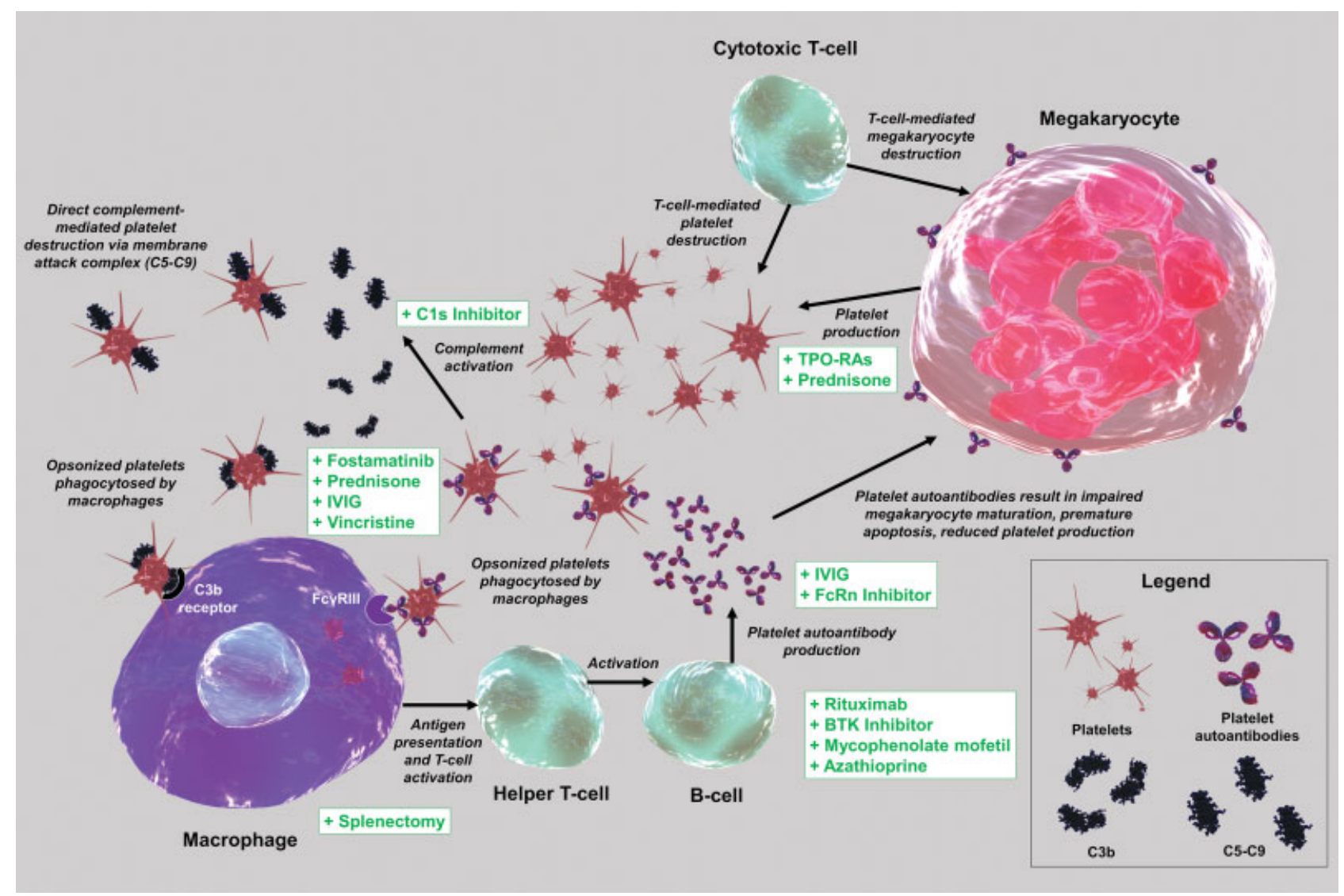

Fig. 1 Pathophysiology of ITP and impact of ITP treatments. IVIG, intravenous immunoglobulin; BTK, Bruton tyrosine kinase; TPO-RA, thrombopoietin receptor agonist; FcRn, neonatal Fc receptor. 
often needed. ${ }^{23}$ Finally, ITP-associated fatigue may respond to treatment and resolve with higher platelet counts. Given the debilitating nature of this fatigue in certain patients, treatment may be indicated. ${ }^{11}$

\section{Initial|Acute Treatments}

The mainstay of initial/acute treatment is corticosteroids, typically either prednisone (administered over a 4- to 8-week course [including taper] with a starting dose of $\sim 0.5-2 \mathrm{mg} / \mathrm{kg}$ daily, to a maximum of $80 \mathrm{mg}$ daily) or high-dose dexamethasone (administered as a pulse of $40 \mathrm{mg}$ daily for 4 days for up to three 4-day cycles). ${ }^{4,5}$ Most responsive patients experience platelet count improvements 2 to 4 days after initiation of corticosteroids, but response may take 5 to 7 days or longer in some patients. Patients experiencing a major bleeding event and those with contraindications or nonresponse to corticosteroids should receive IVIG. Intravenous anti-D immune globulin is another agent that can be used in the acute setting in RhD-positive patients, causing mild hemolysis to reduce platelet destruction in the reticuloendothelial system, but it is not available in many countries now because it may precipitate DIC. Each of these agents has response rates in excess of 70 to $80 \%$ in the newly diagnosed patient.

\section{Corticosteroids}

How corticosteroids improve the platelet count in ITP remains unclear. Studies have shown that corticosteroids reduce platelet autoantibody production and inhibit Fc receptor-mediated clearance by phagocytic cells ${ }^{24}$ but also increase platelet production. ${ }^{25}$ Additionally, corticosteroids may improve vascular integrity in thrombocytopenic states. Thrombocytopenia results in endothelial thinning and fenestrations which may predispose to bleeding; prednisone has been demonstrated to reverse these changes in a rabbit model. ${ }^{26,27}$

Prednisone and dexamethasone are the corticosteroids of choice in ITP. Studies comparing dexamethasone to prednisone or prednisolone have not demonstrated clear superiority of any corticosteroid. ${ }^{28-30}$ In a meta-analysis of trials comparing dexamethasone to prednisone, dexamethasone was found to work faster but did not result in a higher rate of sustained remission. ${ }^{31}$ Either agent remains appropriate to use in most patients; in certain patient groups at higher risk of corticosteroid-associated psychiatric side effects (such as very elderly patients), high-dose dexamethasone should be avoided.

Several studies in newly diagnosed ITP patients have explored the addition of rituximab or TPO-RAs to corticosteroids. Several studies combining rituximab with dexamethasone demonstrated higher remission rates at 6 to 12 months, but these improved remission rates were not sustained. ${ }^{32-37}$ A study of eltrombopag plus dexamethasone in the upfront setting is potentially promising, but additional follow-up is needed. ${ }^{38}$

\section{Intravenous Immunoglobulin}

IVIG reduces Fc receptor-mediated clearance of platelets by the reticuloendothelial system. Several mechanisms have been postulated for this effect, including competition with platelet autoantibodies for FcRn receptor binding, which results in increased platelet autoantibody clearance; binding to FcrRIII on phagocytes, thereby preventing binding of platelet autoantibody immune complexes; and upregulating the inhibitory FcrRIIB on phagocytes. ${ }^{39,40}$

IVIG can be administered either high dose ( $1 \mathrm{~g} / \mathrm{kg}$ daily for 1-2 days) in emergent settings or lower dose (e.g., $0.4 \mathrm{~g} / \mathrm{kg}$ daily for up to 5 days). ${ }^{5}$ It should be used in patients with major bleeding (often in combination with corticosteroids) or in patients who require acute treatment and either cannot tolerate or do not respond to corticosteroids.

\section{Intravenous Anti-RhD Immune Globulin}

IV anti-RhD immune globulin reduces Fc receptor-mediated clearance of autoantibody-coated platelets by creation of a "controlled" red cell hemolysis. Anti-RhD antibody-coated red cells compete with autoantibody-coated platelets for FcrR on phagocytes of the reticuloendothelial system, reducing platelet destruction. Intravenous anti-D immune globulin is licensed for a $50 \mu \mathrm{g} / \mathrm{kg}$ dose but appears to be more effective when administered at a higher $75 \mu \mathrm{g} / \mathrm{kg}$ dose. ${ }^{41,42}$ Essentially all patients will have a modest hemoglobin drop of approximately $1 \mathrm{~g} / \mathrm{dL}$ on average. Anti-RhD is effective only in RhD-positive patients who have not been splenectomized. It is an option in the initial/acute setting but has limited availability. Blood group testing, direct antiglobulin testing, and reticulocyte count should be obtained prior to administering IV anti-D immune globulin. ${ }^{5}$ Since DIC is a potential major adverse effect of this drug, patients should be closely monitored.

\section{Management of Nonresponding Patients in the Initial] Acute Setting}

Patience is important when managing patients in the acute setting. At least 7 to 10 days from the initiation of treatment should pass before declaring failure of corticosteroids and IVIG. ${ }^{4,5}$ In these situations, several options should be considered. The first is reexamination of the diagnosis, which may include bone marrow examination, to ensure that an alternative diagnosis has not been missed. Additionally, other treatment options can be pursued, generally those deferred to subsequent treatment of patients who relapse after initial therapy (discussed in more detail later). Rituximab can be considered, but it often takes several weeks to work. A TPORA can be tried; we favor romiplostim owing to its higher potency ${ }^{43-45}$ and recommend administration of high-dose treatment upfront (5-10 $\mu \mathrm{g} / \mathrm{kg}$ for 1-2 doses). This requires continued patience as TPO-RAs do not work immediately and require a minimum of 5 to 7 days before an effect is seen. Vinca alkaloids (vide infra) might also be considered given their rapid onset of effect, but their use is usually limited by the risk of neuropathy. Emergency splenectomy is another option; this is best reserved for truly treatment-resistant patients and a high degree of confidence that the diagnosis of ITP is correct. Bone marrow examination is advised before performance of emergency splenectomy. ${ }^{4,5}$

Platelet transfusion achieves a transient improvement of $>20 \times 10^{9} / \mathrm{L}$ in a significant minority of bleeding ITP patients, ${ }^{46}$ an effect that may be augmented with concurrent 
administration of IVIG. ${ }^{47}$ Nonspecific hemostatic agents, such as the antifibrinolytic agents tranexamic acid and $\varepsilon$-aminocaproic acid, may also be considered in the acutely bleeding patient.

\section{Management of Pregnant Patients Requiring Treatment}

ITP complicates between 1 in 1,000 and 1 in 10,000 pregnancies, ${ }^{48}$ although it requires treatment only in about a third of cases. ${ }^{49}$ Pregnancy complications, including maternal hemorrhage, fetal loss, and low birthweight, are more common in women with ITP. ${ }^{50,51}$ Neonatal thrombocytopenia may occur due to transplacental passage of platelet autoantibodies. Treatment should be administered for the purpose of maintaining an adequate platelet count in the mother ( $\geq 20 \times 10^{9} / \mathrm{L}$ until close to term, with the goal then adjusted based on delivery procedures and potential requirement for neuraxial anesthesia). ${ }^{5}$ Either corticosteroids or IVIG is appropriate for treatment. In patients unresponsive to either of these agents alone, a combination of corticosteroids plus IVIG can be attempted. ${ }^{52}$ There are inadequate data to recommend other treatments, which in a woman with inadequate response to corticosteroids and/or IVIG must be considered in a case-by-case basis. One such agent generally regarded as safe in pregnancy is azathioprine. ${ }^{5}$ The management of pregnant patients is discussed in more detail in a review by Gernsheimer and colleagues. ${ }^{53}$

\section{Subsequent Treatment of Immune Thrombocytopenia}

While most adult ITP patients respond to corticosteroids and/or IVIG, the majority will relapse following this response and progress to persistent and often chronic ITP. Many of these patients do not require treatment at the time of relapse because they are able to maintain adequate platelet counts without bleeding manifestations. For those patients who do require subsequent treatment, numerous options are available.

\section{Choice of Subsequent Treatment}

Most patients who relapse following initial treatment will again respond to corticosteroids or IVIG, but recurrent or longterm use of these agents is generally not recommended. Chronic corticosteroids administered at doses $>5 \mathrm{mg}$ prednisone daily (or equivalent) results in an unacceptable side-effect burden and should not be used in lieu of other treatments, although some ITP patients can do well for years on low doses of prednisone (2.5-5 mg/day). For patients who progress to chronic ITP, corticosteroids and IVIG remain useful as rescue therapies for bleeding or profound thrombocytopenia.

Current and upcoming international consensus report (ICR) and ASH ITP guidelines generally offer wide latitude in the selection of subsequent treatment in the postrelapse setting. The treatments with the most robust evidence in the subsequent treatment setting are the TPO-RAs romiplostim and eltrombopag, the Syk kinase inhibitor fostamatinib, the antiCD20 agent rituximab, and splenectomy. The proposed ASH 2019 ITP clinical practice guidelines that were unveiled at the
2018 ASH Annual Meeting and Exposition ${ }^{54}$ and made available for public comment list TPO-RAs, rituximab, and splenectomy as favored second-line therapies. Implicit in their analysis was the recognition that therapies previously deemed for "chronic" patients could be considered after 3 months of disease, and that splenectomy should be deferred at least that long if possible. TPO-RAs are recommended over rituximab and rituximab over splenectomy. In comparing TPO-RAs with splenectomy, the merits of each approach are stated, but one is not recommended over the other; rather the updated guidelines advise a joint decision-making process between patient and provider. -Table 2 summarizes the pros and cons of the major therapies considered in the subsequent treatment setting.

\section{Splenectomy}

Splenectomy is effective in ITP by removing the principal site of reticuloendothelial system platelet destruction as well as a major site of platelet autoantibody production. Platelet survival improves over threefold following splenectomy. ${ }^{25}$ The early response rate to splenectomy is approximately $85 \%$, with rapid responses in most patients. ${ }^{55}$ Unfortunately, 20 to $30 \%$ of patients who initially respond to splenectomy will eventually relapse (most in the first year after splenectomy), such that longterm remissions are observed in approximately 60 to $70 \%$ of all patients. ${ }^{55}$ Patients under consideration for splenectomy should be vaccinated for encapsulated organisms (Streptococcus pneumoniae, Haemophilus influenzae, and Neisseria meningitidis).

Following splenectomy in ITP patients, there is an increased risk of venous thromboembolism (VTE) and sepsis. ${ }^{56}$ Since ITP patients already have an increased risk of VTE at baseline relative to the general population, the cumulative VTE risk (including splanchnic vein thrombosis) increases approximately threefold following splenectomy ${ }^{56}$ occurring in 4 to $5 \%$ of patients in one large study. The risk of splanchnic vein thrombosis is over fivefold higher in the 3-month period following splenectomy and the rate of portal or splenic vein thrombosis was $74 \%$ in one study that employed systematic detection with abdominal CT scans between 3 and 7 days following splenectomy. ${ }^{57}$ The incidence of infections leading to sepsis remains persistently elevated by approximately twofold in splenectomized ITP patients relative to their nonsplenectomized counterparts. ${ }^{56}$ Additionally, splenectomy may have other unforeseen consequences. For example, evidence has emerged that the splenic red pulp is the site of a unique undifferentiated monocyte pool that appears to exit the spleen following ischemic cardiac injury and may be important in repairing injured cardiac tissue. ${ }^{58}$ Additionally, a recent study has shown a nearly threefold increased cancer risk in patients following nontraumatic splenectomy. ${ }^{59}$

Therefore, while splenectomy offers the promise of longterm remission in approximately two-thirds of patients, patients need to be informed of these risks and splenectomy should be delayed if possible. We favor a delay of at least 1 year in most patients. This is based on the finding that about onethird of adults with ITP will enter remission with medical therapies in the first year after ITP diagnosis. ${ }^{60}$ In addition, approximately one-third of patients with chronic disease may attain a remission. ${ }^{61}$ With the introduction of novel ITP 
Table 2 Comparison of the primary treatment modalities used for subsequent treatment of immune thrombocytopenia

\begin{tabular}{|l|l|l|l|}
\hline & Splenectomy & TPO-RAs & Rituximab \\
\hline Early response rate & $85 \%$ & $70-80 \%$ & $50-60 \%$ \\
\hline $\begin{array}{l}\text { Sustained } \\
\text { response rate }\end{array}$ & $60-70 \%$ & $70-80 \%$ on treatment & $20 \%$ off treatment \\
\hline Remission rate & $60-70 \%$ & $30-40 \%$ & $20 \%$ \\
\hline Financial burden & Low & High & Moderate \\
\hline $\begin{array}{l}\text { Positive } \\
\text { clinical aspects }\end{array}$ & $\begin{array}{l}\text { Offers long-term remission in } \\
\text { majority of patients } \\
\text { No need for chronic treatment } \\
\text { Avoidance of medication side effects }\end{array}$ & $\begin{array}{l}\text { Well tolerated with high } \\
\text { response rates } \\
\text { Multiple therapeutic options } \\
\text { Avoidance of surgery }\end{array}$ & $\begin{array}{l}\text { No need for chronic treatment } \\
\text { Avoidance of surgery }\end{array}$ \\
\hline $\begin{array}{l}\text { Potential major or } \\
\text { important adverse } \\
\text { events }\end{array}$ & $\begin{array}{l}\text { Operative complications } \\
\text { Immediate and lifetime increased } \\
\text { risk of thromboembolism } \\
\text { (especially splanchnic vein } \\
\text { thrombosis) and infection } \\
\text { Lifetime increased risk of malignancy }\end{array}$ & $\begin{array}{l}\text { Headaches } \\
\text { Hepatotoxicity } \\
\text { (eltrombopag only) } \\
\text { Venous thromboembolism } \\
\text { (theoretical risk) } \\
\text { Bone marrow fibrosis } \\
\text { (low risk, reversible) }\end{array}$ & $\begin{array}{l}\text { Infusion reactions } \\
\text { B cell depletion and infections } \\
\text { leukoencephalopathy (rare) } \\
\text { Delayed neutropenia (rare) }\end{array}$ \\
\hline $\begin{array}{l}\text { Quality-of-life issues } \\
\text { None after initial postsurgical period }\end{array}$ & $\begin{array}{l}\text { Chronic dietary restrictions } \\
\text { (eltrombopag) } \\
\text { Weekly injections } \\
\text { (romiplostim) }\end{array}$ & None \\
\hline
\end{tabular}

Abbreviation: TPO-RA, thrombopoietin receptor agonist.

therapies in the past two decades, the rate of splenectomy has declined precipitously, from approximately $30 \%$ of ITP patients in the United States in the mid-1990s to less than $10 \%$ by $2009 .{ }^{56}$ Prior studies demonstrating durable remissions in 60 to $70 \%$ of patients included many patients undergoing splenectomy as an early treatment following failure of initial corticosteroid-based management. Given that splenectomy is now frequently deferred until several newer medical treatments have been attempted, the population of ITP patients proceeding to splenectomy in modern times may have more treatment-resistant disease. It is unclear if the historic remission rates still apply to these patients.

\section{Thrombopoietin Receptor Agonists}

Thrombopoietin receptor agonists mimic the action of endogenous TPO on megakaryocytes and megakaryocyte precursors, inducing resistance to platelet autoantibody- and lymphocyteinduced apoptosis, thereby promoting the survival, growth, and maturation of megakaryocytes. Therefore, TPO-RAs augment platelet production to compensate for increased platelet turnover. In addition to their efficacy in ITP, these agents can improve platelet counts in chemotherapy-induced thrombocytopenia, myelodysplastic syndrome, periprocedural thrombocytopenia in chronic liver disease, and aplastic anemia (where eltrombopag can induce trilineage responses). ${ }^{62-66}$ Three TPORAs have demonstrated efficacy in ITP: the peptide agent romiplostim and the small molecule agents eltrombopag and avatrombopag. - Table 3 presents an overview of the differences between each of the agents. One or more phase III randomized, controlled trials have been performed evaluating each of these agents; the results of these trials are summarized in - Table 4. Regardless of agent, TPO-RAs have a higher overall response rate (70-80\%) than other agents used for subsequent treatment of ITP but typically require prolonged durations of use. In patients with refractory ITP (relapse post-splenectomy requiring treatment), the response rate is approximately 40 to $60 \%{ }^{67-69}$ While extended durations of use are expected, a significant minority of responding patients demonstrate durable, long-standing remissions after prolonged TPO-RA treatment. ${ }^{60,70}$

\section{Predicting Response to Thrombopoietin Receptor Agonists}

Evidence has emerged that elevated baseline endogenous TPO levels (which are normal in $>75 \%$ of ITP patients) may predict response to the TPO-RAs in ITP ${ }^{14,71,72}$ in as much the same fashion as endogenous erythropoietin levels can predict response to erythropoiesis-stimulating agents. In a study utilizing a well-validated ELISA-based TPO assay with a normal reference range of $\leq 100 \mathrm{pg} / \mathrm{mL}$, patients with significant TPO elevations ( $>200 \mathrm{pg} / \mathrm{mL}$ ) were unlikely to respond well to either eltrombopag or romiplostim, whereas patients with a normal TPO level were very likely to respond to either agent. ${ }^{14}$ While a study investigating the predictive value of TPO levels for response to avatrombopag in ITP has not yet been published, TPO values do predict response to avatrombopag in patients with chronic liver disease. ${ }^{73}$ Given the cost and duration of time required to titrate these agents to clinical effect, if validated in additional studies, the use of TPO levels to predict treatment response may emerge as a valuable tool in treatment planning.

\section{Agent Selection}

In selecting between the TPO-RAs, numerous factors are considered. Eltrombopag and avatrombopag are orally administered in contrast to romiplostim which requires weekly 
Table 3 Comparison of the thrombopoietin receptor agonists used in immune thrombocytopenia treatment

\begin{tabular}{|c|c|c|c|}
\hline & Romiplostim & Eltrombopag & Avatrombopag \\
\hline Molecular structure & Peptide & Small molecule & Small molecule \\
\hline TPO receptor site of action & Extracellular domain & Transmembrane domain & Transmembrane domain \\
\hline Route of administration & Subcutaneous & Oral & Oral \\
\hline Dosing frequency $^{\mathrm{a}}$ & Weekly & Daily $^{\mathrm{b}}$ & Daily \\
\hline Relevant food interactions & $\mathrm{N} / \mathrm{A}$ & Yes & No \\
\hline $\begin{array}{l}\text { Average U.S. wholesale } \\
\text { price }\end{array}$ & $\begin{array}{l}\$ 2,230.30 \text { per } 250 \mu \mathrm{g} \text { vial } \\
\$ 4,460.59 \text { per } 500 \mu \mathrm{g} \text { vial }\end{array}$ & $\begin{array}{l}\text { \$197.06 per tablet } \\
(12.5 \mathrm{mg} \text { or } 25 \mathrm{mg}) \\
\$ 356.61 \text { per tablet }(50 \mathrm{mg}) \\
\$ 534.92 \text { per tablet }(75 \mathrm{mg})\end{array}$ & $\$ 356.40$ per $20 \mathrm{mg}$ tablet \\
\hline Current indications & $\begin{array}{l}\text { Chronic ITP } \\
\text { (adults and children) }\end{array}$ & $\begin{array}{l}\text { Chronic ITP } \\
\text { (adults and children) } \\
\text { Hepatitis C-associated } \\
\text { thrombocytopenia } \\
\text { Severe aplastic anemia }\end{array}$ & $\begin{array}{l}\text { Periprocedural thrombocytopenia } \\
\text { in chronic liver disease patients } \\
\text { Chronic ITP (adults) }\end{array}$ \\
\hline
\end{tabular}

Abbreviations: CLD, chronic liver disease; FDA, United States Food and Drug Administration; ITP, immune thrombocytopenia; N/A, not applicable; TPO, thrombopoietin.

aper drug label.

bMay sometimes be given much less frequently. ${ }^{80}$

subcutaneous injections. Eltrombopag absorption is dramatically reduced by fat or divalent cation consumption, functionally requiring a 4- to 6-hour fasted window around its administration unless strict dietary restrictions are followed. ${ }^{74,75}$ Avatrombopag, by contrast, absorbs better with food. ${ }^{45,76}$ Romiplostim is considerably more potent than the oral TPO-RAs in healthy volunteers, ${ }^{43-45}$ and may be more potent in ITP patients as well ${ }^{77}$; clinical response to this agent appears to be impacted less by mild baseline TPO level elevations than eltrombopag. ${ }^{14}$ Failure of one TPO-RA does not preclude use of another; switching from one TPO-RA to another is successful in many patients. ${ }^{78}$

\section{Dosing of Thrombopoietin Receptor Agonists}

Per the prescribing information, eltrombopag is initiated at a dose of $50 \mathrm{mg}$ daily in adults ( $25 \mathrm{mg}$ daily in those of East Asian descent) and dose (12.5-75 mg daily) is titrated to platelet count. ${ }^{79}$ This agent has a half-life of 35 hours in ITP patients, so alternative dosing regimens administering the medication less frequently than once daily are reasonable and have been described in adult ITP patients. ${ }^{80}$ Romiplostim is initiated at a dose of $1 \mu \mathrm{g} / \mathrm{kg} /$ week per the U.S. prescribing information, which advises uptitration by $1 \mu \mathrm{g} / \mathrm{kg} /$ week until an acceptable platelet count is achieved. ${ }^{81}$ However, most patients require doses $\geq 3 \mathrm{mg} / \mathrm{kg} /$ week to respond; so, in clinical practice (and in one of the phase III studies of romiplostim ${ }^{82}$ ), $3 \mu \mathrm{g} / \mathrm{kg} /$ week may be used as the starting dose with low thrombocytosis risk. ${ }^{83}$ Avatrombopag was recently FDA-approved for ITP in the United States. Initial dosing is $20 \mathrm{mg}$ once daily, based on data from a phase III clinical trial demonstrating excellent platelet response rates with this dose. ${ }^{84}$

\section{Adverse Effects of Thrombopoietin Receptor Agonists}

TPO-RAs are generally well tolerated in ITP patients, with mild to moderate headache as the most common side effect. ${ }^{67,82,84}$
Interval transaminase monitoring is advised for patients on eltrombopag due to the risk of hepatotoxicity. ${ }^{79}$ While thrombotic events, bone marrow fibrosis, and leukemogenesis are a theoretical concern with these agents, studies have not found elevated risks of these concerning side effects in ITP patients. Eltrombopag and romiplostim do not result in platelet hyperreactivity or spontaneous platelet aggregation ${ }^{85,86}$ and numerous large randomized, controlled studies of ITP patients have not demonstrated a significantly increased risk of venous or arterial thrombotic events in patients receiving TPO-RAs as compared with placebo. ${ }^{67,82,87,88}$ Bone marrow studies in patients receiving TPO-RAs for extended periods show a very low risk $(\sim 5 \%)$ of marrow reticulin fibrosis (which readily reverses on agent discontinuation) and essentially no risk of irreversible marrow collagen fibrosis. ${ }^{89,90}$ Additionally, there is no evidence of leukemic potential for use of TPO-RAs in any disorder, including myelodysplastic syndrome, where there is no clearly increased risk of leukemic progression with several years of follow-up. ${ }^{91}$ Therefore, bone marrow examination is not indicated before treatment or for monitoring during treatment.

\section{Rituximab}

Rituximab is a chimeric anti-CD20 monoclonal antibody that depletes the B-cells that produce platelet autoantibodies. It is not FDA approved for use in ITP but has been a commonly employed ITP treatment for nearly two decades. Studies of mostly heavily pretreated patients demonstrate an overall response rate of approximately 40 to $70 \%$ with 4 weekly doses of $375 \mathrm{mg} / \mathrm{m}^{2}$ of rituximab, ${ }^{92-94}$ although sustained remissions were much less common. A meta-analysis of five trials containing a total of 376 adults with ITP demonstrated a $57 \%$ overall remission rate with rituximab, but remission rate at 1 year was $38 \%$ and remission rate at 5 years was only $21 \%{ }^{37}$ Alternate dosing of rituximab (both higher and lower dosing schedules) 


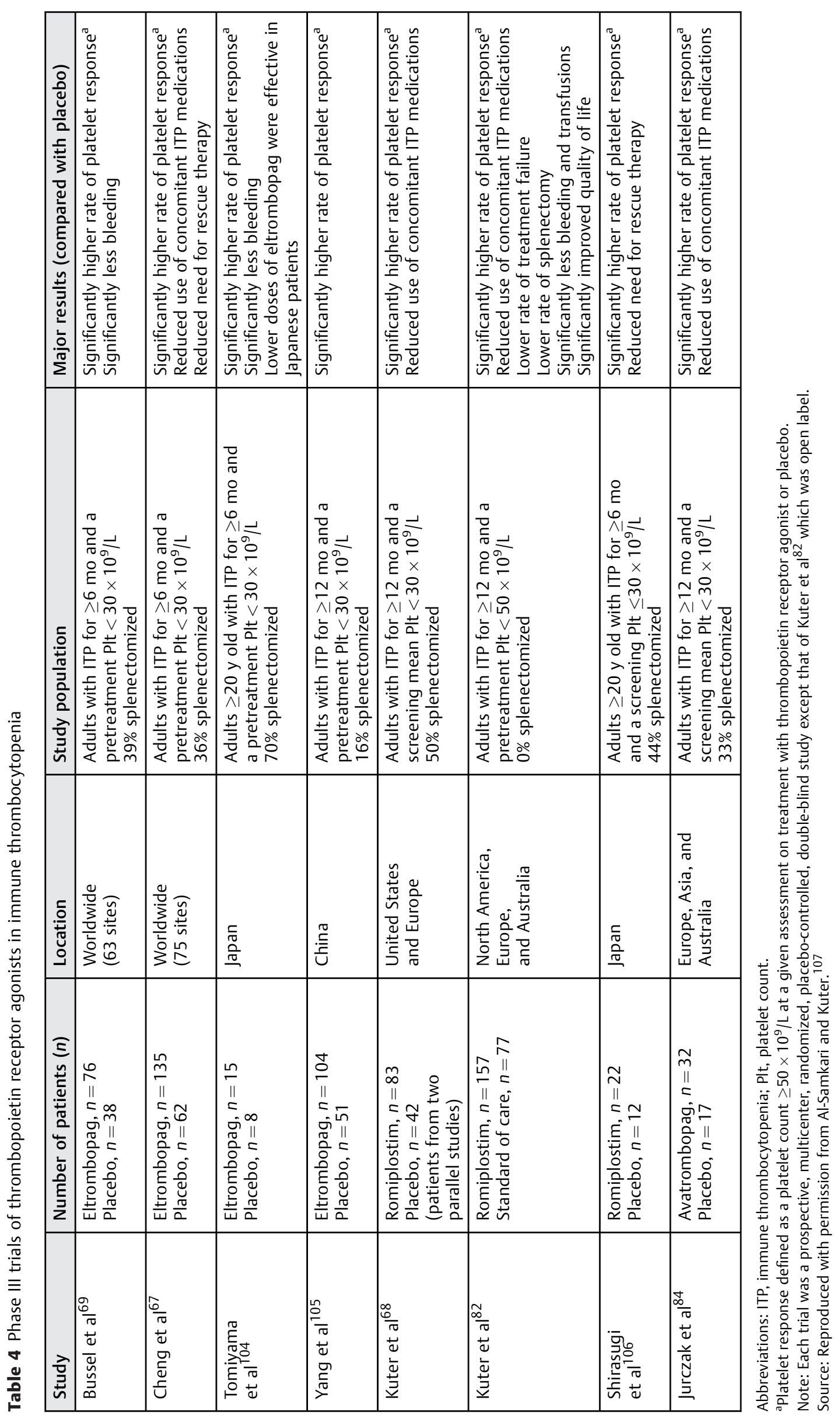




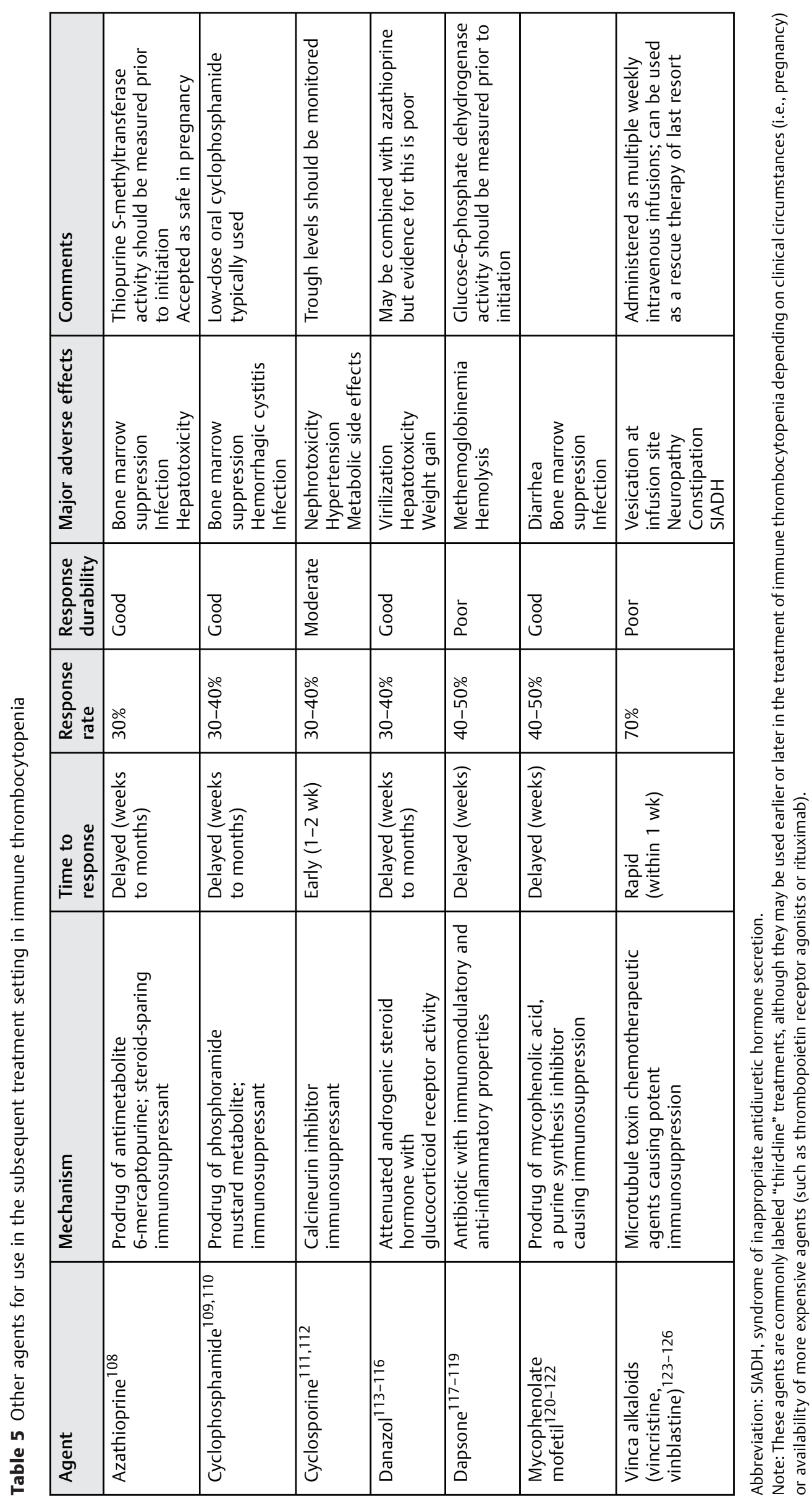


has been attempted ${ }^{95-99}$; it is unclear if these approaches are superior to standard-dose rituximab with respect to either effectiveness or safety. Rituximab may result in acute infusion reactions, but the most consequential potential long-term adverse events (especially with recurrent treatment episodes over time) are chronic B cell depletion and hypogammaglobulinemia with attendant infection risk, chronic neutropenia, and progressive multifocal leukoencephalopathy. ${ }^{100}$

\section{Fostamatinib}

Fostamatinib is a prodrug of the Syk (spleen tyrosine kinase) inhibitor tamatinib (R406). ${ }^{101}$ As Syk is active in numerous inflammatory cells including splenic macrophages, fostamatinib inhibits Fc-receptor-mediated clearance of autoantibody-coated platelets in the spleen. In two double-blind randomized controlled trials of heavily pretreated patients with severe or refractory ITP and a median disease duration of 8.5 years, the overall response rate (one or more platelet counts $\geq 50 \times 10^{9} / \mathrm{L}$ over the 12 -week trial period) was $43 \%$ in the fostamatinib arm versus $14 \%$ in the placebo arm and the stable response rate (at least 4 of 6 biweekly platelet counts $\geq 50 \times 10^{9} / \mathrm{L}$ ) was $18 \%$ in the fostamatinib arm and $2 \%$ in the placebo arm. ${ }^{102}$ Responses were durable in over half of patients maintained on fostamatinib. ${ }^{103}$ As is the case for several tyrosine kinase inhibitors, hypertension and gastrointestinal side effects (nausea, diarrhea) were common. Fostamatinib is initiated at $100 \mathrm{mg}$ twice daily and can be uptitrated to $150 \mathrm{mg}$ twice daily after 4 weeks if the platelet count is inadequate. If there is no response after 4 weeks at the highest dose, the drug should be discontinued.

\section{Other Treatment Options}

Numerous other medical therapies with immunosuppressive or immunomodulatory effects have been examined in ITP. - Table 5 summarizes these agents. Studies of these agents are typically small and often retrospective; the overall response rate for these drugs is approximately 20 to $50 \%$, depending on the agent and the ITP population, with lower response rates in more heavily pretreated patients with longer disease duration. Prolonged treatment is necessary to maintain responses for all these agents, except Vinca alkaloids.

\section{Conclusion}

Diagnosis of ITP has changed little in the past decade, as there remains no reliable biomarker or gold-standard diagnostic test. While the search for such a test continues, diagnosis will remain clinical and possible only with exclusion of other causes of thrombocytopenia. ITP treatment has advanced considerably in the past decade, with the introduction of TPO-RAs and fostamatinib. As numerous additional agents are currently under development for ITP treatment, continued advances are likely moving forward.

\section{Authors' Contributions}

H.A. drafted the manuscript, created the tables and figures, and contributed to the concept and design, critical revision of the intellectual content, and final approval. D.J.K. contributed to the concept and design, critical revision of the intellectual content, and final approval.

\section{Conflicts of Interest}

H.A. reports research funding (Agios, Dova) and consultancy (Agios, Dova, Moderna). H.A. is the recipient of the National Hemophilia Foundation-Shire Clinical Fellowship Award, which provides partial salary support. D.J.K. reports research funding (Protalex, Bristol-Myers Squibb, Rigel, Bioverativ, Agios, Syntimmune, Principia, and Alnylam) and consultancy (ONO, Pfizer, 3SBios, Eisai, GlaxoSmithKline, Genzyme, Shire, Alexion, Amgen, Shionogi, Rigel, Syntimmune, MedImmune, Novartis, Bioverativ, Argenx, and Zafgen).

\section{Acknowledgments}

The authors thank Dr. Maher Al-Samkari for his assistance with the 3D-rendered cells used in -Fig. 1.

\section{References}

1 Harrington WJ, Minnich V, Hollingsworth JW, Moore CV. Demonstration of a thrombocytopenic factor in the blood of patients with thrombocytopenic purpura. J Lab Clin Med 1951;38(01):1-10

2 Harker LA, Finch CA. Thrombokinetics in man. J Clin Invest 1969; 48(06):963-974

3 McMillan R, Wang L, Tomer A, Nichol J, Pistillo J. Suppression of in vitro megakaryocyte production by antiplatelet autoantibodies from adult patients with chronic ITP. Blood 2004;103(04):1364-1369

4 Neunert C, Lim W, Crowther M, Cohen A, Solberg L Jr, Crowther MA; American Society of Hematology. The American Society of Hematology 2011 evidence-based practice guideline for immune thrombocytopenia. Blood 2011;117(16):4190-4207

5 Provan D, Stasi R, Newland AC, et al. International consensus report on the investigation and management of primary immune thrombocytopenia. Blood 2010;115(02):168-186

6 Frederiksen H, Schmidt K. The incidence of idiopathic thrombocytopenic purpura in adults increases with age. Blood 1999;94 (03):909-913

7 Neylon AJ, Saunders PW, Howard MR, Proctor SJ, Taylor PR; Northern Region Haematology Group. Clinically significant newly presenting autoimmune thrombocytopenic purpura in adults: a prospective study of a population-based cohort of 245 patients. Br J Haematol 2003;122(06):966-974

8 Butros LJ, Bussel JB. Intracranial hemorrhage in immune thrombocytopenic purpura: a retrospective analysis. J Pediatr Hematol Oncol 2003;25(08):660-664

9 Cohen YC, Djulbegovic B, Shamai-Lubovitz O, Mozes B. The bleeding risk and natural history of idiopathic thrombocytopenic purpura in patients with persistent low platelet counts. Arch Intern Med 2000;160(11):1630-1638

10 Newton JL, Reese JA, Watson SI, et al. Fatigue in adult patients with primary immune thrombocytopenia. Eur J Haematol 2011; 86(05):420-429

11 Hill QA, Newland AC. Fatigue in immune thrombocytopenia. Br J Haematol 2015;170(02):141-149

12 Vrbensky JR, Moore JE, Arnold DM, Smith JW, Kelton JG, Nazy I. The sensitivity and specificity of platelet autoantibody testing in immune thrombocytopenia: a systematic review and meta-analysis of a diagnostic test. J Thromb Haemost 2019;17(05):787-794

13 Al-Samkari H, Kuter DJ. Antiplatelet antibody testing in immune thrombocytopenia and Evans syndrome: longitudinal serologic evolution and relation to clinical features [abstract]. Blood 2018; 132(Suppl 1):1137 
14 Al-Samkari H, Kuter DJ. Thrombopoietin level predicts response to treatment with eltrombopag and romiplostim in immune thrombocytopenia. Am J Hematol 2018;93(12):1501-1508

15 Rodeghiero F, Stasi R, Gernsheimer T, et al. Standardization of terminology, definitions and outcome criteria in immune thrombocytopenic purpura of adults and children: report from an international working group. Blood 2009;113(11):2386-2393

16 Portielje JE, Westendorp RG, Kluin-Nelemans HC, Brand A. Morbidity and mortality in adults with idiopathic thrombocytopenic purpura. Blood 2001;97(09):2549-2554

17 Sailer T, Lechner K, Panzer S, Kyrle PA, Pabinger I. The course of severe autoimmune thrombocytopenia in patients not undergoing splenectomy. Haematologica 2006;91(08):1041-1045

18 Slichter SJ, Harker LA. Thrombocytopenia: mechanisms and management of defects in platelet production. Clin Haematol 1978;7(03):523-539

19 Slichter SJ, Kaufman RM, Assmann SF, et al. Dose of prophylactic platelet transfusions and prevention of hemorrhage. $\mathrm{N}$ Engl J Med 2010;362(07):600-613

20 Lacey JV, Penner JA. Management of idiopathic thrombocytopenic purpura in the adult. Semin Thromb Hemost 1977;3(03):160-174

21 Chantarangkul V, Clerici M, Bressi C, Tripodi A. Standardization of the endogenous thrombin potential measurement: how to minimize the effect of residual platelets in stored plasma. $\mathrm{Br} \mathrm{J}$ Haematol 2004;124(03):355-357

22 Harker LA, Slichter SJ. The bleeding time as a screening test for evaluation of platelet function. N Engl J Med 1972;287(04): 155-159

23 Nagrebetsky A, Al-Samkari H, Davis NM, Kuter DJ, WienerKronish JP. Perioperative thrombocytopenia: evidence, evaluation, and emerging therapies. Br J Anaesth 2019;122(01):19-31

24 Shulman NR, Weinrach RS, Libre EP, Andrews HL. The role of the reticuloendothelial system in the pathogenesis of idiopathic thrombocytopenic purpura. Trans Assoc Am Physicians 1965;78:374-390

25 Gernsheimer T, Stratton J, Ballem PJ, Slichter SJ. Mechanisms of response to treatment in autoimmune thrombocytopenic purpura. N Engl J Med 1989;320(15):974-980

26 Kitchens CS. Amelioration of endothelial abnormalities by prednisone in experimental thrombocytopenia in the rabbit. JClin Invest 1977;60(05):1129-1134

27 Kitchens CS, Weiss L. Ultrastructural changes of endothelium associated with thrombocytopenia. Blood 1975;46(04):567-578

28 Nakazaki K, Hosoi M, Hangaishi A, Ichikawa M, Nannya Y, Kurokawa M. Comparison between pulsed high-dose dexamethasone and daily corticosteroid therapy for adult primary immune thrombocytopenia: a retrospective study. Intern Med 2012;51(08):859-863

29 Bae SH, Ryoo HM, Lee WS, et al. High dose dexamethasone vs. conventional dose prednisolone for adults with immune thrombocytopenia: a prospective multicenter phase III trial [abstract]. Blood 2010;116(21):3687

30 Wei Y, Ji XB, Wang YW, et al. High-dose dexamethasone vs prednisone for treatment of adult immune thrombocytopenia: a prospective multicenter randomized trial. Blood 2016;127(03): 296-302, quiz 370

31 Mithoowani S, Gregory-Miller K, Goy J, et al. High-dose dexamethasone compared with prednisone for previously untreated primary immune thrombocytopenia: a systematic review and meta-analysis. Lancet Haematol 2016;3(10):e489-e496

32 Gómez-Almaguer D, Tarín-Arzaga L, Moreno-Jaime B, et al. High response rate to low-dose rituximab plus high-dose dexamethasone as frontline therapy in adult patients with primary immune thrombocytopenia. Eur J Haematol 2013;90(06):494-500

33 Gudbrandsdottir S, Birgens HS, Frederiksen H, et al. Rituximab and dexamethasone vs dexamethasone monotherapy in newly diagnosed patients with primary immune thrombocytopenia. Blood 2013;121(11):1976-1981

34 Zaja F, Baccarani M, Mazza P, et al. Dexamethasone plus rituximab yields higher sustained response rates than dexamethasone monotherapy in adults with primary immune thrombocytopenia. Blood 2010;115(14):2755-2762

35 Chapin J, Lee CS, Zhang H, Zehnder JL, Bussel JB. Gender and duration of disease differentiate responses to rituximab-dexamethasone therapy in adults with immune thrombocytopenia. Am J Hematol 2016;91(09):907-911

36 Bussel JB, Lee CS, Seery C, et al. Rituximab and three dexamethasone cycles provide responses similar to splenectomy in women and those with immune thrombocytopenia of less than two years duration. Haematologica 2014;99(07):1264-1271

37 Chugh S, Darvish-Kazem S, Lim W, et al. Rituximab plus standard of care for treatment of primary immune thrombocytopenia: a systematic review and meta-analysis. Lancet Haematol 2015;2 (02):e75-e81

38 Zhang L, Zhang M, Du X, Cheng Y, Cheng G. Eltrombopag plus pulsed dexamethasone as first line therapy for subjects with immune thrombocytopenic purpura (ITP) [abstract]. Blood 2018;132(Suppl 1):733

39 Nimmerjahn F, Ravetch JV. Anti-inflammatory actions of intravenous immunoglobulin. Annu Rev Immunol 2008;26: 513-533

40 Deng R, Balthasar JP. Pharmacokinetic/pharmacodynamic modeling of IVIG effects in a murine model of immune thrombocytopenia. JPharm Sci 2007;96(06):1625-1637

41 Newman GC, Novoa MV, Fodero EM, Lesser ML, Woloski BM, Bussel JB. A dose of $75 \mathrm{microg} / \mathrm{kg} / \mathrm{d}$ of i.v. anti-D increases the platelet count more rapidly and for a longer period of time than $50 \mathrm{microg} / \mathrm{kg} / \mathrm{d}$ in adults with immune thrombocytopenic purpura. Br J Haematol 2001;112(04):1076-1078

42 Tarantino MD, Young G, Bertolone SJ, et al; Acute ITP Study Group. Single dose of anti-D immune globulin at $75 \mathrm{microg} / \mathrm{kg}$ is as effective as intravenous immune globulin at rapidly raising the platelet count in newly diagnosed immune thrombocytopenic purpura in children. J Pediatr 2006;148(04):489-494

43 Kumagai Y, Fujita T, Ozaki M, et al. Pharmacodynamics and pharmacokinetics of AMG 531, a thrombopoiesis-stimulating peptibody, in healthy Japanese subjects: a randomized, placebocontrolled study. JClin Pharmacol 2007;47(12):1489-1497

44 Jenkins JM, Williams D, Deng Y, et al. Phase 1 clinical study of eltrombopag, an oral, nonpeptide thrombopoietin receptor agonist. Blood 2007;109(11):4739-4741

45 Nomoto M, Pastino G, Rege B, Aluri J, Ferry J, Han D. Pharmacokinetics, pharmacodynamics, pharmacogenomics, safety, and tolerability of avatrombopag in healthy Japanese and white subjects. Clin Pharmacol Drug Dev 2018;7(02):188-195

46 Carr JM, Kruskall MS, Kaye JA, Robinson SH. Efficacy of platelet transfusions in immune thrombocytopenia. Am J Med 1986;80 (06):1051-1054

47 Spahr JE, Rodgers GM. Treatment of immune-mediated thrombocytopenia purpura with concurrent intravenous immunoglobulin and platelet transfusion: a retrospective review of 40 patients. Am J Hematol 2008;83(02):122-125

48 American College of Obstetricians and Gynecologists. ACOG Practice Bulletin: Thrombocytopenia in pregnancy. Number 6, September 1999. Clinical management guidelines for obstetrician-gynecologists. Int J Gynaecol Obstet 1999;67(02):117-128

49 Webert KE, Mittal R, Sigouin C, Heddle NM, Kelton JG. A retrospective 11-year analysis of obstetric patients with idiopathic thrombocytopenic purpura. Blood 2003;102(13):4306-4311

50 Al-Jama FE, Rahman J, Al-Suleiman SA, Rahman MS. Outcome of pregnancy in women with idiopathic thrombocytopenic purpura. Aust N Z J Obstet Gynaecol 1998;38(04):410-413

51 Wyszynski DF, Carman WJ, Cantor AB, et al. Pregnancy and birth outcomes among women with idiopathic thrombocytopenic purpura. J Pregnancy 2016;2016:8297407

52 Nicolescu A, Vladareanu AM, Voican I, Onisai M, Vladareanu R. Therapeutic options for immune thrombocytopenia (ITP) during pregnancy. Maedica (Buchar) 2013;8(02):182-188 
53 Gernsheimer T, James AH, Stasi R. How I treat thrombocytopenia in pregnancy. Blood 2013;121(01):38-47

54 Neunert CE, Cooper N. Evidence-based management of immune thrombocytopenia: ASH guideline update. Hematology (Am Soc Hematol Educ Program) 2018;2018(01):568-575

55 Schwartz J, Leber MD, Gillis S, Giunta A, Eldor A, Bussel JB. Long term follow-up after splenectomy performed for immune thrombocytopenic purpura (ITP). Am J Hematol 2003;72(02): 94-98

56 Boyle S, White RH, Brunson A, Wun T. Splenectomy and the incidence of venous thromboembolism and sepsis in patients with immune thrombocytopenia. Blood 2013;121(23):4782-4790

57 Morbieu C, Brunetti F, Baranès L, et al. Systematic detection of portal or splenic vein thrombosis after splenectomy for immune cytopenia. Am J Hematol 2018;93(07):E170-E172

58 Swirski FK, Nahrendorf M, Etzrodt M, et al. Identification of splenic reservoir monocytes and their deployment to inflammatory sites. Science 2009;325(5940):612-616

59 Sun LM, Chen HJ, Jeng LB, Li TC, Wu SC, Kao CH. Splenectomy and increased subsequent cancer risk: a nationwide populationbased cohort study. Am J Surg 2015;210(02):243-251

60 Newland A, Godeau B, Priego V, et al. Remission and platelet responses with romiplostim in primary immune thrombocytopenia: final results from a phase 2 study. Br J Haematol 2016;172 (02):262-273

61 Marshall AL, Scarpone R, De Greef M, Bird R, Kuter DJ. Remissions after long-term use of romiplostim for immune thrombocytopenia. Haematologica 2016;101(12):e476-e478

62 Desmond R, Townsley DM, Dumitriu B, et al. Eltrombopag restores trilineage hematopoiesis in refractory severe aplastic anemia that can be sustained on discontinuation of drug. Blood 2014;123(12):1818-1825

63 Afdhal NH, Dusheiko GM, Giannini EG, et al. Eltrombopag increases platelet numbers in thrombocytopenic patients with HCV infection and cirrhosis, allowing for effective antiviral therapy. Gastroenterology 2014;146(02):442-52.e1

64 Al-Samkari H, Marshall AL, Goodarzi K, Kuter DJ. The use of romiplostim in treating chemotherapy-induced thrombocytopenia in patients with solid tumors. Haematologica 2018;103 (04):e169-e172

65 Al-Samkari H, Marshall AL, Goodarzi K, Kuter DJ. Romiplostim for the management of perioperative thrombocytopenia. $\mathrm{Br} \mathrm{J}$ Haematol 2018;182(01):106-113

66 Kantarjian H, Fenaux P, Sekeres MA, et al. Safety and efficacy of romiplostim in patients with lower-risk myelodysplastic syndrome and thrombocytopenia. JClin Oncol 2010;28(03): 437-444

67 Cheng G, Saleh MN, Marcher C, et al. Eltrombopag for management of chronic immune thrombocytopenia (RAISE): a 6-month, randomised, phase 3 study. Lancet 2011;377(9763):393-402

68 Kuter DJ, Bussel JB, Lyons RM, et al. Efficacy of romiplostim in patients with chronic immune thrombocytopenic purpura: a double-blind randomised controlled trial. Lancet 2008;371 (9610):395-403

69 Bussel JB, Provan D, Shamsi T, et al. Effect of eltrombopag on platelet counts and bleeding during treatment of chronic idiopathic thrombocytopenic purpura: a randomised, double-blind, placebo-controlled trial. Lancet 2009;373(9664):641-648

70 González-López TJ, Pascual C, Álvarez-Román MT, et al. Successful discontinuation of eltrombopag after complete remission in patients with primary immune thrombocytopenia. Am J Hematol 2015;90(03):E40-E43

71 Makar RS, Zhukov OS, Sahud MA, Kuter DJ. Thrombopoietin levels in patients with disorders of platelet production: diagnostic potential and utility in predicting response to TPO receptor agonists. Am J Hematol 2013;88(12):1041-1044

72 Kuter DJ, Meibohm A, Lopez A. TPO concentrations and response to romiplostim. Am J Hematol 2014;89(12):1155-1156
73 Nomoto M, Ferry J, Hussein Z. Population pharmacokinetic/ pharmacodynamic analyses of avatrombopag in patients with chronic liver disease and optimal dose adjustment guide with concomitantly administered CYP3A and CYP2C9 inhibitors. J Clin Pharmacol 2018;58(12):1629-1638

74 Williams DD, Peng B, Bailey CK, et al. Effects of food and antacids on the pharmacokinetics of eltrombopag in healthy adult subjects: two single-dose, open-label, randomized-sequence, crossover studies. Clin Ther 2009;31(04):764-776

75 Wire MB, Bruce J, Gauvin J, et al. A randomized, open-label, 5-period, balanced crossover study to evaluate the relative bioavailability of eltrombopag powder for oral suspension (PfOS) and tablet formulations and the effect of a high-calcium meal on eltrombopag pharmacokinetics when administered with or 2 hours before or after PfOS. Clin Ther 2012;34(03):699-709

76 Al-Samkari H. Avatrombopag maleate for the treatment of periprocedural thrombocytopenia in patients with chronic liver disease. Drugs Today (Barc) 2018;54(11):647-655

77 Al-Samkari H, Kuter DJ. Relative potency of the thrombopoietin receptor agonists eltrombopag, avatrombopag and romiplostim in a patient with chronic immune thrombocytopenia. $\mathrm{Br} \mathrm{J}$ Haematol 2018;183(02):168

78 Kuter DJ, Macahilig C, Grotzinger KM, et al. Treatment patterns and clinical outcomes in patients with chronic immune thrombocytopenia (ITP) switched to eltrombopag or romiplostim. Int J Hematol 2015;101(03):255-263

79 GlaxoSmithKline. Promacta (Eltrombopag) [Prescribing Information]. Research Triangle Park, NC2017

80 Al-Samkari H, Kuter DJ. An alternative intermittent eltrombopag dosing protocol for the treatment of chronic immune thrombocytopenia. Br J Clin Pharmacol 2018;84(11):2673-2677

81 Amgen I. Nplate (Romiplostim) [Prescribing Information]. Thousand Oaks, CA: Amgen October 2017

82 Kuter DJ, Rummel M, Boccia R, et al. Romiplostim or standard of care in patients with immune thrombocytopenia. N Engl J Med 2010;363(20):1889-1899

83 Steurer M, Quittet P, Papadaki HA, et al. A large observational study of patients with primary immune thrombocytopenia receiving romiplostim in European clinical practice. Eur J Haematol 2017;98(02):112-120

84 Jurczak W, Chojnowski K, Mayer J, et al. Phase 3 randomised study of avatrombopag, a novel thrombopoietin receptor agonist for the treatment of chronic immune thrombocytopenia. $\mathrm{Br} \mathrm{J}$ Haematol 2018;183(03):479-490

85 Psaila B, Bussel JB, Linden MD, et al. In vivo effects of eltrombopag on platelet function in immune thrombocytopenia: no evidence of platelet activation. Blood 2012;119(17):4066-4072

86 Al-Samkari H, Van Cott EM, Kuter DJ. Platelet aggregation response in immune thrombocytopenia patients treated with romiplostim. Ann Hematol 2019;98(03):581-588

87 Bussel JB, Kuter DJ, Pullarkat V, Lyons RM, Guo M, Nichol JL. Safety and efficacy of long-term treatment with romiplostim in thrombocytopenic patients with chronic ITP. Blood 2009;113 (10):2161-2171

88 Cines DB, Gernsheimer T, Wasser J, et al. Integrated analysis of long-term safety in patients with chronic immune thrombocytopaenia (ITP) treated with the thrombopoietin (TPO) receptor agonist romiplostim. Int J Hematol 2015;102(03):259-270

89 Kuter DJ, Mufti GJ, Bain BJ, Hasserjian RP, Davis W, Rutstein M. Evaluation of bone marrow reticulin formation in chronic immune thrombocytopenia patients treated with romiplostim. Blood 2009;114(18):3748-3756

90 Janssens A, Rodeghiero F, Anderson D, et al. Changes in bone marrow morphology in adults receiving romiplostim for the treatment of thrombocytopenia associated with primary immune thrombocytopenia. Ann Hematol 2016;95(07):1077-1087

91 Kantarjian HM, Fenaux P, Sekeres MA, et al. Long-term follow-up for up to 5 years on the risk of leukaemic progression in 
thrombocytopenic patients with lower-risk myelodysplastic syndromes treated with romiplostim or placebo in a randomised double-blind trial. Lancet Haematol 2018;5(03):e117-e126

92 Ghanima W, Khelif A, Waage A, et al; RITP Study Group. Rituximab as second-line treatment for adult immune thrombocytopenia (the RITP trial): a multicentre, randomised, double-blind, placebocontrolled trial. Lancet 2015;385(9978):1653-1661

93 Pasa S, Altintas A, Cil T, Danis R, Ayyildiz O. The efficacy of rituximab in patients with splenectomized refractory chronic idiopathic thrombocythopenic purpura. J Thromb Thrombolysis 2009;27(03):329-333

94 Červinek L, Černá O, Čaniga M, et al. Efficacy of rituximab in primary immune thrombocytopenia: an analysis of adult pretreated patients from everyday hematological practice. Int J Hematol 2012;96(05):594-599

95 Mahévas M, Ebbo M, Audia S, et al. Efficacy and safety of rituximab given at $1,000 \mathrm{mg}$ on days 1 and 15 compared to the standard regimen to treat adult immune thrombocytopenia. Am J Hematol 2013;88(10):858-861

96 Tran H, Brighton T, Grigg A, et al. A multi-centre, single-arm, open-label study evaluating the safety and efficacy of fixed dose rituximab in patients with refractory, relapsed or chronic idiopathic thrombocytopenic purpura (R-ITP1000 study). Br J Haematol 2014;167(02):243-251

97 Khellaf M, Charles-Nelson A, Fain O, et al. Safety and efficacy of rituximab in adult immune thrombocytopenia: results from a prospective registry including 248 patients. Blood 2014;124 (22):3228-3236

98 Zaja F, Vianelli N, Volpetti S, et al. Low-dose rituximab in adult patients with primary immune thrombocytopenia. Eur J Haematol 2010;85(04):329-334

99 Zaja F, Volpetti S, Chiozzotto M, et al. Long-term follow-up analysis after rituximab salvage therapy in adult patients with immune thrombocytopenia. Am J Hematol 2012;87(09):886-889

100 Vikse J, Jonsdottir K, Kvaløy JT, Wildhagen K, Omdal R. Tolerability and safety of long-term rituximab treatment in systemic inflammatory and autoimmune diseases. Rheumatol Int 2019; 39(06):1083-1090

101 Markham A. Fostamatinib: first global approval. Drugs 2018;78 (09):959-963

102 Bussel J, Arnold DM, Grossbard E, et al. Fostamatinib for the treatment of adult persistent and chronic immune thrombocytopenia: results of two phase 3 , randomized, placebo-controlled trials. Am J Hematol 2018;93(07):921-930

103 Bussel JB, Arnold DM, Boxer MA, et al. Long-term fostamatinib treatment of adults with immune thrombocytopenia during the phase 3 clinical trial program. Am J Hematol 2019;94(05):546-553

104 Tomiyama Y, Miyakawa Y, Okamoto S, et al. A lower starting dose of eltrombopag is efficacious in Japanese patients with previously treated chronic immune thrombocytopenia. JThromb Haemost 2012;10(05):799-806

105 Yang R, Hou M, Li J, et al. Effect of eltrombopag on platelet response and safety results in Chinese adults with chronic ITP-primary result of a phase III study [abstract]. Blood 2014;124(21):1464

106 Shirasugi Y, Ando K, Miyazaki K, et al. Romiplostim for the treatment of chronic immune thrombocytopenia in adult Japanese patients: a double-blind, randomized Phase III clinical trial. Int J Hematol 2011;94(01):71-80

107 Al-Samkari H, Kuter DJ. Optimal use of thrombopoietin receptor agonists in immune thrombocytopenia. Ther Adv Hematol 2019. Doi: $10.1177 / 2040620719841735$ [epub ahead of print]

108 Quiquandon I, Fenaux P, Caulier MT, Pagniez D, Huart JJ, Bauters F. Re-evaluation of the role of azathioprine in the treatment of adult chronic idiopathic thrombocytopenic purpura: a report on 53 cases. Br J Haematol 1990;74(02):223-228
109 Verlin M, Laros RK Jr, Penner JA. Treatment of refractory thrombocytopenic purpura with cyclophosphamine. Am J Hematol 1976;1(01):97-104

110 Pizzuto J, Ambriz R. Therapeutic experience on 934 adults with idiopathic thrombocytopenic purpura: multicentric trial of the Cooperative Latin American group on hemostasis and thrombosis. Blood 1984;64(06):1179-1183

111 Choudhary DR, Naithani R, Mahapatra M, Kumar R, Mishra P, Saxena R. Efficacy of cyclosporine as a single agent therapy in chronic idiopathic thrombocytopenic purpura. Haematologica 2008;93(10):e61-e62, discussion e63

112 Kappers-Klunne MC, van't Veer MB. Cyclosporin A for the treatment of patients with chronic idiopathic thrombocytopenic purpura refractory to corticosteroids or splenectomy. $\mathrm{Br} \mathrm{J} \mathrm{Hae-}$ matol 2001;114(01):121-125

113 Fenaux P, Quiquandon I, Huart JJ, Caulier MT, Bauters F. The role of danazol in the treatment of refractory idiopathic thrombocytopenic purpura. A report of 22 cases. Nouv Rev Fr Hematol 1990; 32(02):143-146

114 Li HQ, Zhang L, Zhao H, Ji LX, Yang RC. Chronic idiopathic thrombocytopenic purpura in adult Chinese patients: a retrospective single-centered analysis of 1791 cases. Chin Med J (Engl) 2005;118(01):34-37

115 Liu W, Gu X, Fu R, et al. The effect of danazol in primary immune thrombocytopenia: an analysis of a large cohort from a single center in China. Clin Appl Thromb Hemost 2016;22(08):727-733

116 Maloisel F, Andrès E, Zimmer J, et al. Danazol therapy in patients with chronic idiopathic thrombocytopenic purpura: long-term results. Am J Med 2004;116(09):590-594

117 Damodar S, Viswabandya A, George B, Mathews V, Chandy M, Srivastava A. Dapsone for chronic idiopathic thrombocytopenic purpura in children and adults-a report on 90 patients. Eur J Haematol 2005;75(04):328-331

118 Godeau B, Durand JM, Roudot-Thoraval F, et al. Dapsone for chronic autoimmune thrombocytopenic purpura: a report of 66 cases. Br J Haematol 1997;97(02):336-339

119 Zaja F, Marin L, Chiozzotto M, Puglisi S, Volpetti S, Fanin R. Dapsone salvage therapy for adult patients with immune thrombocytopenia relapsed or refractory to steroid and rituximab. Am J Hematol 2012;87(03):321-323

120 Hou M, Peng J, Shi Y, et al. Mycophenolate mofetil (MMF) for the treatment of steroid-resistant idiopathic thrombocytopenic purpura. Eur J Haematol 2003;70(06):353-357

121 Taylor A, Neave L, Solanki S, et al. Mycophenolate mofetil therapy for severe immune thrombocytopenia. Br J Haematol 2015;171 (04):625-630

122 Zhang WG, Ji L, Cao XM, et al. Mycophenolate mofetil as a treatment for refractory idiopathic thrombocytopenic purpura. Acta Pharmacol Sin 2005;26(05):598-602

123 Ahn YS, Harrington WJ, Mylvaganam R, Allen LM, Pall LM. Slow infusion of Vinca alkaloids in the treatment of idiopathic thrombocytopenic purpura. Ann Intern Med 1984;100(02): 192-196

124 Facon T, Caulier MT, Wattel E, Jouet JP, Bauters F, Fenaux P. A randomized trial comparing vinblastine in slow infusion and by bolus i.v. injection in idiopathic thrombocytopenic purpura: a report on 42 patients. Br J Haematol 1994;86(03):678-680

125 Fenaux P, Quiquandon I, Caulier MT, Simon M, Walter MP, Bauters F. Slow infusions of vinblastine in the treatment of adult idiopathic thrombocytopenic purpura: a report on 43 cases. Blut 1990;60(04):238-241

126 Park YH, Yi HG, Lee MH, Kim CS, Lim JH. Clinical efficacy and tolerability of vincristine in splenectomized patients with refractory or relapsed immune thrombocytopenia: a retrospective single-center study. Int J Hematol 2016;103(02):180-188 